to answer in this book. Very little evidence is presented for their efficacy al though there is a reasonably long list of references concerning this particular marital counselling approach. As an introductory book that outlines the behavioural approach to marriage counselling this well written and entertaining volume serves a valuable function. If you $c$ an persuade your wife to lend you the money you $\mathrm{c}$ an send to Research Press, $2612 \mathrm{~N}$. Mattis, Champaign, Illinois 61820, U.S.A., who handle foreign orders on a Proforma basis but don't tell your in-1aws.

Howard Rankin -

Addiction Research Unit.

Institute of Psychiatry.

\title{
BRANCH ACTIVITIES
}

LEEDS 30th January, 1976 - High Royds Hospital, Menston. One-day workshop on "Behavioural Methods in Psychiatric Nursing". Speakers: David Skidmore, Nursing Officer, Stanley Royd Hospital, Wakefield; Gerald Rosentha11, Research Advisory Nurse, Rehabilitation Unit, Stanley Royd Hospital, Wakefie1d; John Ha11, Research Fellow, Leeds University, Department of Psychiatry.

11 th February - 5.00 p.m. - Psychology Department, Leeds University - Dr. Patricia Gillan - "Sexual Dysfunction".

NORTH WALES On Wednesday 10th December, 1975, an inaugural meeting of the North Wales Branch of the B.A.B.P. was held in Colwyn Bay. An interim committee of 8 people was elected. The Chairman will be Mr. N. Barlow, Child Guidance Clinic, Old Colwyn, C1wyd, and the Secretary, Dr. C. Cullen, Bryn-y-Neuadd Hospital, Llanf airfechan.

\section{ANNOUNCEMENTS}

POSTGRADUATE COURSE ON BEHAVIOURAL PSYCHOTHERAPY. February 2, 3, 4, 1976: Institute of Psychiatry, The Maudsley Hospital, London, SE5.

This is a non-residential 3-day course for psychiatrists with a minimum of 2years clinical experience. It will involve lectures, seminars and videotape demonstrations of the principles and practice of behavioural psychotherapy in adult patients with neurotic, marital and sexual problems. The course will be run by Dr. M. Crowe and Dr. I.M. Marks. Fee £28. Applications, together with curriculum vitae stating degrees and experience, to Dr. Marks.

\section{THE SOCIETY FOR PSYCHOTHERAPY}

Award for an original contribution to Psychotherapy

The Society is a registered Charitable Trust set up for the promotion of psychotherapeutic knowledge and the encouragement of the study and practice of Psychotherapy. In pursuance of this the Society offers $\$ 100$ (or $\$ 150$ in case of joint authorship) for the best paper describing research, or an original contribution in the field of psychotherapy excluding chemical or physical treatment. Material which has already been published is not eligible. Those submitting papers must be members of professional bodies concerned with psychotherapy or of recognised academic standing. The Society may publish papers of sufficient merit. Papers should be sent by May 1st, 1976, to the Secretary, 411, Upper Richmond Road, London, SW15. The Society will consider giving support and $f$ inancial help for relevant research projects. 